\title{
Knowledge, attitude and practice towards pharmacovigilance among postgraduate medical students at a tertiary care hospital: a cross sectional questionnaire based study
}

\author{
Vishnu K.*, Mamatha K. R., Jayanthi C. R.
}

Department of Pharmacology, Bangalore Medical College and Research Institute, Bangalore, India

Received: 06 February 2017 Accepted: 06 March 2017

*Correspondence to:

Dr. Vishnu K.,

Email:

emailtovishnu@gmail.com

Copyright: (c) the author(s), publisher and licensee Medip Academy. This is an openaccess article distributed under the terms of the Creative Commons Attribution NonCommercial License, which permits unrestricted noncommercial use, distribution, and reproduction in any medium, provided the original work is properly cited.

\begin{abstract}
Background: Adverse drug reaction (ADR) is major global health problem affecting both children and adults. ADRs are among the leading cause of mortality and morbidity leading to prolonged hospitalization. Hence, spontaneous reporting of ADRs by healthcare professionals forms the backbone of pharmacovigilance. Therefore, there is an urgent need for sensitization about drug safety monitoring among healthcare professionals (HCPs).

Methods: A cross sectional questionnaire based study was conducted among 200 postgraduate medical students between April 2016 and May 2016 using a pre-validated questionnaire. Descriptive statistics was used for analysis.

Results: Among 200 questionnaires distributed, only 150 provided responses reflecting a response rate of $75 \%$. The postgraduates who understood the definition of adverse drug reaction and pharmacovigilance were $90 \%$ and $64 \%$ respectively. The most encouraging finding was $97 \%$ of postgraduates thought that reporting an ADR was necessary which in turn increases the patient safety. $60 \%$ postgraduates were unaware that the nurses and pharmacists also had the responsibility of reporting ADR. The postgraduates who encountered ADRs during clinical practice were $79 \%$ whereas reporting was only $2 \%$.

Conclusions: This study suggests that even though majority of postgraduates have better knowledge and attitude towards pharmacovigilance and ADR, the practice of reporting ADRs is inadequate. Therefore, there is an urgent need for educational intervention in the form of training programmes and continued medical education (CME) periodically to encourage ADR reporting among the postgraduates.
\end{abstract}

Keywords: Adverse drug reaction, Knowledge, Pharmacovigilance, Practice

\section{INTRODUCTION}

Modern approaches and newer medicines have changed the way in which diseases are treated and prevented. However, inspite of all their benefits, adverse effects due to medicines are common cause of morbidity and mortality and are responsible for a significant number of hospital admissions ranging from $0.2 \%$ to $24 \% .^{1-3}$ The World Health Organization (WHO) defines ADR "as a response to a drug which is noxious, unintended, and which occurs at doses normally used in man for the prophylaxis, diagnosis, or therapy of disease or for modification of physiological function". ${ }^{4}$ ADRs lead to number of consequences like prolonged hospital stay, increase in the cost of treatment and increased risk of death. ${ }^{3}$ Hence, safety monitoring of medicines is the need of the hour and responsibility of all stakeholders in the healthcare system. ${ }^{5}$

Detection of common or uncommon ADRs requires vigilance which led to the establishment of wellorganized pharmacovigilance system. ${ }^{6}$ According to WHO, Pharmacovigilance (PV) is defined as the science and activities relating to detection, assessment, understanding and prevention of adverse effects or any other drug-related problems. ${ }^{7}$ Pharmacovigilance is still in its infancy in India and there exists very limited knowledge about this discipline. Several studies carried out in India have concluded that there is a lack of knowledge and awareness about pharmacovigilance among doctors, practitioners, and students. ${ }^{8}$ Spontaneous ADR reporting by healthcare professionals forms the 
backbone of pharmacovigilance system. However, gross under-reporting of ADR is a major hurdle. ${ }^{6}$ Therefore, there is an urgent need for sensitization about drug safety monitoring among healthcare professionals especially the postgraduates who are future practitioners. Hence, this study was undertaken to assess the knowledge, attitude and practices (KAP) of the young residents regarding ADR reporting and pharmacovigilance.

The objective of the study was to assess the knowledge, attitude and practice towards pharmacovigilance among postgraduate medical students.

\section{METHODS}

This was a cross sectional questionnaire based study which was conducted between April 2016 and May 2016. The present study was conducted among 200 postgraduate medical students willing to participate in the study from various preclinical, paraclinical and clinical departments of Bangalore Medical College \& Research Institute, Bangalore, India.

Before the study, the knowledge, attitude and practice questionnaire toward pharmacovigilance and ADRs was developed and all questions were peer viewed by expert faculties from pharmacology and clinical departments of our institute. The questionnaire was structured and prevalidated and used for data collection as a research tool. The final questionnaire contained 4 items to check knowledge, 7 items for attitude, and 3 items to study practices. In addition, space was provided to give suggestions.

\section{Study procedure}

All study participants were contacted directly in their respective department, explained the purpose of the study and distributed the questionnaires, given appropriate time to fill the questionnaire and hand it back. Any clarification needed in understanding the questionnaires was provided. The filled up questionnaires were collected back and analyzed, question wise and their percentage value was calculated. Data was analyzed using descriptive statistics.

\section{RESULTS}

Among 200 questionnaires distributed, only 150 provided their responses reflecting a response rate of $75 \%$. Definition of ADR and definition of PV were aware by $90 \%$ and $64 \%$ of postgraduates respectively (Figure 1).

$20 \%$ of the postgraduates were of the opinion that all healthcare professionals- doctors, nurses, and pharmacists are responsible for reporting ADR (Figure 2).

$47 \%$ of postgraduates were unaware that pharmacovigilance includes herbal products, medical devices and vaccines (Figure 3 ).

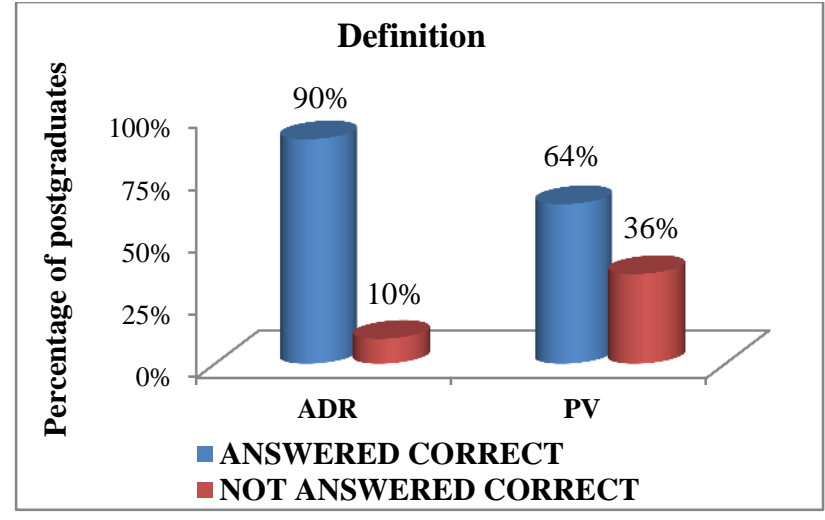

Figure 1: Definition of adverse drug reaction (ADR) and pharmacovigilance (PV).

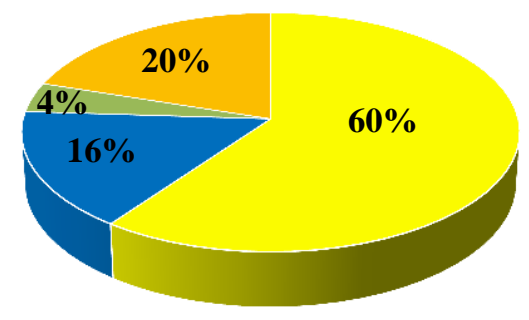

DOCTORS $₫$ NURSES $₫$ PHARMACISTS $₫$ ALL HCP's

Figure 2: Health care professionals (HCP's) responsible for reporting an ADR.
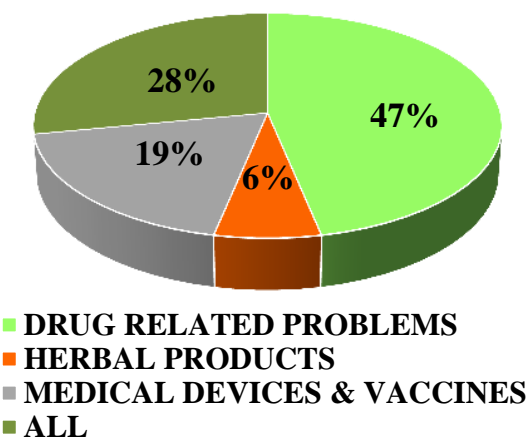

Figure 3: Elements of Pharmacovigilance.

In the present study, 97\% felt that reporting of ADR was necessary, as it will contribute to patient safety, thus benefiting both patients and doctors. 59\% of the postgraduates were of the opinion that reporting an ADR was mandatory, $65 \%$ thought that reporting ADRs was a professional obligation whereas $64 \%$ of postgraduates were willing to report an ADR (Figure 4 and 5).

$21 \%$ were aware about the fact that ADR monitoring centre should be established in every hospital (Figure 6). 


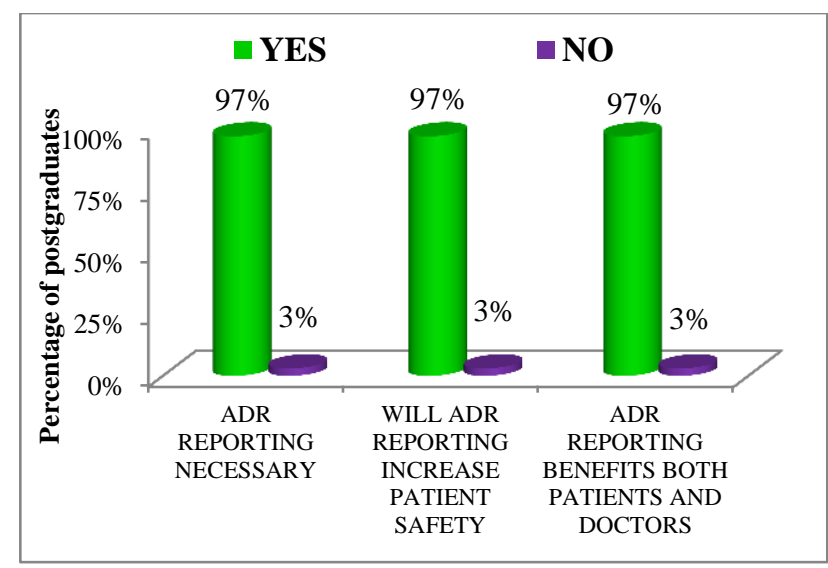

Figure 4: Attitude of postgraduates towards ADR reporting.

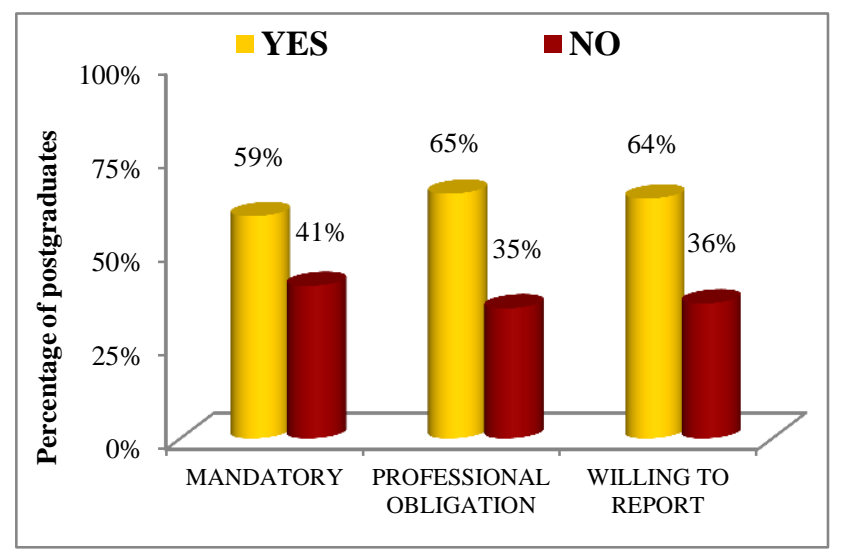

Figure 5: Attitude of postgraduates regarding ADR reporting.

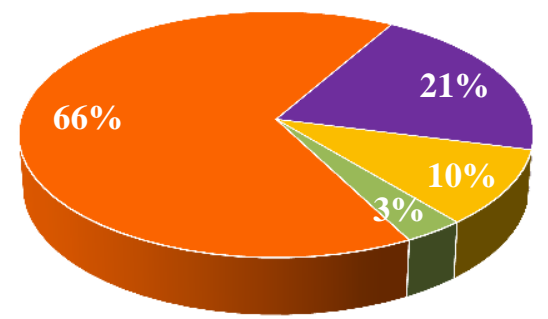

- EVERY HOSPITAL

NOT NECESSARY IN EVERY HOSPITAL

- ONE IN A CITY

- DEPENDS ON NUMBER OF BEDS IN HOSPITAL

\section{Figure 6: Attitude-Establishing ADR} monitoring centre.

In this study, among the postgraduates who encountered ADRs (79.30\%) during clinical practice, only $2 \%$ of postgraduates reported an ADR. 39\% of postgraduates were trained to report an ADR (Figure 7 and 8).

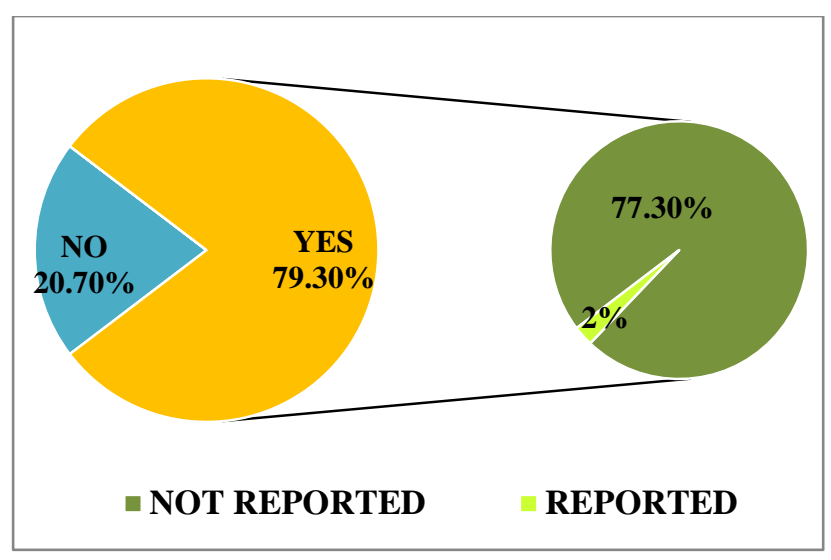

Figure 7: Postgraduates who have encountered ADR and reported.

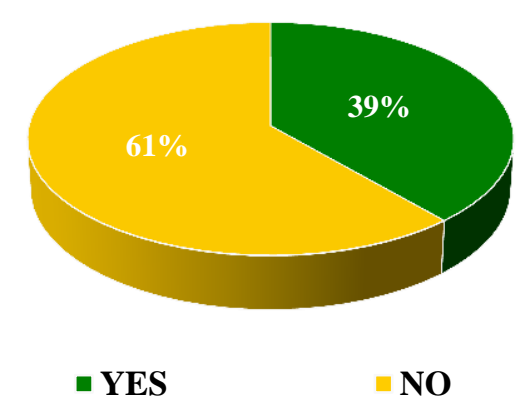

Figure 8: Postgraduates trained to report an ADR.

\section{DISCUSSION}

Reporting of ADRs is an essential component of pharmacovigilance and is crucial to the safety surveillance of marketed medicinal products. ADRs contribute significantly to morbidity and mortality in clinical practice with its associated economic consequences. ${ }^{9}$

In a country like India, with a large population and diverse genetic pool, it is necessary to introduce a standard pharmacovigilance programme. Pharmacovigilance programme of India (PvPI) was started in 1982. ${ }^{8}$ Since 2011, Indian Pharmacopoeia Commission (IPC) has been working as National coordination centre (NCC) which has made a rapid progress in ADR monitoring in India since 5 years. ${ }^{10}$ Assessing the knowledge about pharmacovigilance among healthcare professionals, not only re-sensitizes them to the process but also provides information about the lacunae that is hindering the system. The knowledge of healthcare professionals about pharmacovigilance has been evaluated by various studies, but reporting the same exclusively by postgraduates is limited.

In the present study, majority of the postgraduates were able to recall the definition of ADR (90\%) and 
pharmacovigilance $(64 \%)$ which is better than the results reported by Chetty $\mathrm{S}$ et al, which showed $64 \%$ and $62 \%$ respectively and contrast to a study done by Rehan HS et al, which showed that resident doctors had good knowledge about definition of pharmacovigilance (87\%) compared to ADR $(35 \%) .{ }^{11,12}$ Understanding the definition of ADR is highly essential to detect an ADR and to differentiate ADRs from drug overdosing and other medical conditions.

Postgraduates taking part in the study were aware of the fact that the reporting of an ADR was the responsibility of medical professionals mainly doctors, but the awareness that other health care professionals like the nurses (16\%), and pharmacists (4\%) could do so was low. These findings correlate with the study done by Gupta $\mathrm{P}$ et al. ${ }^{13}$ Lack of knowledge regarding by whom ADR should be reported could be one of the factors for underreporting. The contribution of India to the WHO global individual case safety reports database is $3 \% .^{10}$ In India, $64.4 \%$ physicians reported ADRs, followed by $15.1 \%$ of pharmacists and $20.4 \%$ other health care professionals including nurses and physiotherapists, while $0.016 \%$ of non-health care professionals reported ADRs to PvPI between July 2011 to December 2012. ${ }^{14}$ Few respondents were aware that pharmacovigilance includes not only drug related problems, but also includes other products like herbal products, medical devices and vaccines. These findings were akin to the previous study conducted by Chandrakapure AR et al. ${ }^{8}$ It should be understood that PV encompasses all allopathic drugs and also includes herbal products, blood products, medical devices and vaccines. Interactions between herbs and drugs may increase or decrease the pharmacological/toxicological effects of either component. Due to lack of knowledge about reporting drug-herb interactions, the prevalence of them is stated to be low, though it is substantial. Vaccine PV is important as it detects the adverse effects to the individual as well as its impact on immunisation. Majority of postgraduates in the survey agreed that reporting ADRs was necessary, would increase patient safety and benefits both patients and doctors. Similar views have been expressed in many studies. A study conducted by Upadhyaya HB et al, found that about $93 \%$ and $92 \%$ of postgraduates agreed that reporting ADRs was necessary and would increase the patient safety respectively. ${ }^{15}$ In another study by Kamtane RA et al, 93\% of the doctors believed that ADR reporting would benefit the patients. ${ }^{16}$ This reveals the concerns of the health care professionals about patient safety. ADRs being the fourth leading cause of mortality worldwide, PV activities could help in minimising them in future. Though majority of postgraduates felt that ADR reporting is mandatory and a professional obligation, but only $64 \%$ were willing to report ADRs. Dharmadhikari PP et al, reported that $52 \%$ of doctors agreed to make ADR reporting mandatory and Kulkarni MD et al, reported that $68 \%$ of doctors were of the opinion that reporting an ADR was a professional obligation.,17 Chandrakapure $\mathrm{AR}$ et al, revealed that $88 \%$ of doctors were willing to report an $\mathrm{ADR}^{8}$ This shows that there is a gap in conversion of knowledge of ADR reporting to practice. Many studies have reported various reasons like lack of time/ knowledge/ work overload, non-availability of forms, opinion that a single report not enough to make any difference, no financial incentives, apprehension that serious ADRs are already documented and associated legal issues prevents them from reporting an ADR. Hence training and logistics of ADR reporting should be improved to facilitate reporting. An encouraging step to promote ADR reporting in the form of a mobile application was introduced by PvPI in 2015.

In this study, majority of the postgraduates (79\%) were unaware about the fact that ADR monitoring centre should be established in every hospital. In India, 179 teaching hospitals including corporate hospitals have been identified as Adverse drug reaction monitoring centres (AMCs). ${ }^{10}$ It is essential to establish AMCs in every hospital as it will function towards promoting the safe use of medicines by contributing to appropriate education in pharmacovigilance and training activities. Among $79.30 \%$ of postgraduates who have encountered ADRs during clinical practice, only $2 \%$ of postgraduates have reported ADRs which is in accordance with the results obtained by Gupta $\mathrm{P}$ et al, where $2.9 \%$ of doctors have reported ADRs. ${ }^{13}$ Most importantly, the huge difference between the ADR experienced and ADR reported by healthcare professionals was evident. However, $39 \%$ of postgraduates were trained to report an ADR which is better compared to previous studies conducted by Chandrakapure AR et al and Dharmadhikari PP et al where only $26 \%$ and $11 \%$ of doctors have been trained to report an ADR respectively. ${ }^{8,3}$ ADR reporting after inception of PvPI improved from 3,215 in 2010 to $1,49,607$ in 2015 . NCC has identified nine regional centres in India to provide continuous training about pharmacovigilance. This improvement seen in five years could be the result of continuous training of health care professionals about ADR reporting as well as communication through newsletters, articles in scientific journals and national newspapers. ${ }^{10}$ In view of these results, to improve spontaneous reporting rates, the authors suggest to organize training programmes, an uncomplicated reporting system with quick feedback regarding their specific report and also all other reports received by the pharmacovigilance system. Gestures like acknowledgement of the receipt of the report and an appreciation note would motivate them to continue the pharmacovigilance activities.

\section{Limitations}

The study findings cannot be generalised to wider healthcare professionals as it was conducted only among postgraduate students in our centre during a particular period. 


\section{CONCLUSION}

This study suggests that even though majority of postgraduates have better knowledge and attitude towards pharmacovigilance and ADR, the practice of reporting ADRs is inadequate. The postgraduates felt ADR reporting to be important, but only a few had reported an ADR. Therefore, there is a great need for educational intervention in the form of training programmes periodically which will lay a solid foundation to actively participate in pharmacovigilance in their future practices. Pharmacologists have the primary responsibility to conduct these training sessions to clarify the role of various healthcare professionals in pharmacovigilance, the events to be looked for and reported and to address the various perceived obstacles to spontaneous reporting, these sessions will hopefully fill the observed lacunae in knowledge and practices. ADR reporting should be made an integral part of the clinical activities in order to improve the patient care.

\section{ACKNOWLEDGEMENTS}

The authors would like to thank all the postgraduates students working in Bangalore Medical College and Research Institute for participating in this study.

Funding: No funding sources

Conflict of interest: None declared

Ethical approval: The study was approved by the Institutional Ethics Committee

\section{REFERENCES}

1. Lazarou J, Pomeranz BH, Corey PN. Incidence of adverse drug reactions in hospitalized patients: A meta-analysis of prospective studies. JAMA. 1998;279(15):1200-5.

2. Classen DC, Pestotnik SL, Evans RS, Lloyd JF, Burke JP. Adverse drug events in hospitalized patients. Excess length of stay, extra costs, and attributable mortality. JAMA. 1997;277(4):301-6.

3. Dharmadhikari PP, Date AP, Patil KS. Knowledge, attitude and practice among healthcare professionals of adverse drug reactions reporting in a tertiary care centre. Int J Basic Clin Pharmacol. 2015;4(2):300-5.

4. World Health Organization. Safety of Medicines. A guide to detecting and reporting adverse drug reactions. Geneva, Switzerland: World Health Organization;2002.

5. Guidance document for spontaneous adverse drug reaction reporting. India: Indian Pharmacopoeia Commission. 2014;80.

6. Bansode AA, Zad VR, Sawat SD, Dudhal KS Awareness about Pharmacovigilance among Resident doctors in a tertiary care hospital. Journal of Evolution of Medical and Dental Sciences. 2015;4(2):207-10.
7. WHO. World Health Organization. The importance of pharmacovigillance. Safety Monitoring of Medicinal Products. Essential Medicines and Health Products Information Portal. Geneva: WHO. 2002;152.

8. Chandrakapure AR, Giri SP, Khan IN, Mateenuddin M, Faheem M. Pharmacovigilance: a study to evaluate knowledge, attitude and practices of and impact of educational intervention among doctors in teaching hospital, in rural area of Jalna, India. Int $\mathbf{J}$ Basic Clin Pharmacol. 2015;4(3):427-31.

9. Karelia BN, Piparava KG. Knowledge, attitude and practice of pharmacovigilance among private healthcare professionals of Rajkot city. Int $\mathbf{J}$ Basic Clin Pharmacol. 2014;3(1):50-3.

10. Kalaiselvan V, Thota P, Singh GN. Pharmacovigilance Programme of India: Recent developments and future perspectives. Indian $\mathbf{J}$ Pharmacol. 2016;48(6):624-8.

11. Chetty S, Parida A, Adiga S, Bairy KL. Knowledge, attitude and practice of health care professionals towards adverse drug reaction reporting in a south Indian teaching hospital. World Journal of Pharmaceutical Research. 2014;3(3):4263-71.

12. Rehan HS, Sah RK, Chopra D. Comparison of knowledge, attitude and practices of resident doctors and nurses on adverse drug reaction monitoring and reporting in a tertiary care hospital. Indian $\mathbf{J}$ Pharmacol. 2012;44(6):699-703.

13. Gupta P, Udupa A. Adverse Drug Reaction Reporting and Pharmacovigilance: Knowledge, Attitudes and Perceptions amongst Resident Doctors. Journal of Pharmaceutical Sciences and Research. 2011;3(2):1064-9.

14. Kalaiselvan V, Prasad T, Bisht A, Singh S, Singh GN. Adverse drug reactions reporting culture in Pharmacovigilance Programme of India. Indian $\mathbf{J}$ Med Res. 2014;140(4):563-4.

15. Upadhyaya HB, Vora MB, Nagar JG, Patel PB. Knowledge, attitude and practices toward pharmacovigilance and adverse drug reactions in postgraduate students of tertiary care hospital in Gujarat. J Adv Pharm Technol Res. 2015;6(1):29-34.

16. Kamtane RA, Jayawardhani V. Knowledge, attitude and perception of physicians towards adverse drug reaction (ADR) reporting: A pharmacoepidemiological study. Asian J Pharm Clin Res. 2012;5(3):210-4.

17. Kulkarni MD, Baig MS, Chandaliya KC, Doifode SM, Razvi SU, Sidhu NS. Knowledge, attitude and practice of pharmacovigilance among prescribers of government medical college and hospital, Aurangabad (Maharashtra). International journal of pharmacology and therapeutics. 2013;3(3):10-8.

Cite this article as: Vishnu $\mathrm{K}$, Mamatha $\mathrm{KR}$, Jayanthi CR. Knowledge, attitude and practice towards pharmacovigilance among postgraduate medical students at a tertiary care hospital: a cross sectional questionnaire based study. Int $\mathrm{J}$ Basic Clin Pharmacol 2017;6:968-72. 